\title{
Association between dietary fibre:carbohydrate intake ratio and insulin resistance in Japanese adults without type 2 diabetes
}

\author{
Nobuhisa Morimoto ${ }^{1,2}$, Chikako Kasuga ${ }^{1}$, Airi Tanaka ${ }^{1}$, Keiko Kamachi ${ }^{1}$, Masumi Ai $^{3}$, \\ Kevin Y. Urayama ${ }^{4,5}$ and Akira Tanaka ${ }^{1 *}$ \\ ${ }^{1}$ Nutrition Clinic, Kagawa Nutrition University, Tokyo, 170-8481, Japan \\ ${ }^{2}$ Department of Professional Development, Tokyo Medical and Dental University, Tokyo, 113-8519, Japan \\ ${ }^{3}$ Department of Insured Medical Care Management, Tokyo Medical and Dental University, Tokyo, 113-8519, Japan \\ ${ }^{4}$ Department of Social Medicine, National Center for Child Health and Development, Tokyo, 157-8535, Japan \\ ${ }^{5}$ Graduate School of Public Health, St. Luke's International University, Tokyo, 104-8560, Japan \\ (Submitted 13 April 2017 - Final revision received 1 December 2017 - Accepted 11 December 2017)
}

\section{Abstract}

An easily understandable index that measures the quality of carbohydrate may aid people in adopting dietary habits that improve their glucose tolerance. We aimed to evaluate the relationship between a ratio of dietary fibre to carbohydrate intakes (fibre:carbohydrate ratio (F:C-R)) and glucose tolerance cross-sectionally and longitudinally. Subjects were 190 Japanese men and women without type 2 diabetes (mean age 55.4 years) who participated in a 5-month diet and exercise programme. We compared baseline anthropometric, dietary and metabolic profiles between those with higher F:C-R and those with lower ratios. Multivariable regression analyses were performed to examine the associations between the F:C-R and homoeostasis model of assessment for insulin resistance (HOMA-IR) and HbA1c at baseline and between changes in the F:C-R and changes in HOMA-IR and HbA1c over the 5-month period. At baseline, the higher F:C-R group had significantly lower body weight, lean body mass, fasting insulin level and HOMA-IR as compared with the lower F:C-R group. The two groups had similar intakes of carbohydrate and fat, whereas protein intake was greater in the high F:C-R group. Baseline F:C-R was not significantly associated with HOMA-IR or HbA1c at the beginning of the study in multivariable models. Increases in the ratio during the 5-month programme was associated with reductions in HbA1c $(P<0 \cdot 001)$. These findings highlight the potential utility of the F:C-R in strategies aimed at type 2 diabetes prevention.

Key words: Carbohydrate: Fibre: Diabetes prevention: Insulin resistance

Diabetes presents a significant health challenge across the globe, mainly affecting middle-aged and elderly populations ${ }^{(1)}$. Type 2 diabetes is associated with fatty liver disease and $\mathrm{CVD}^{(2,3)}$. Obesity has been recognised as an important risk factor for insulin resistance and type 2 diabetes $^{(1)}$. Numerous studies have searched for effective weight loss interventions that normalise glucose tolerance $e^{(4,5)}$.

Excess energy intake and certain dietary habits, such as a high-fat diet and a high-fructose diet, are associated with increased risk of obesity and metabolic disturbance, including type 2 diabetes and fatty liver ${ }^{(6-10)}$. Assessing the significance of relative proportions of macronutrient intake on health outcomes has become an active area of research. Recent randomised trials demonstrated more favourable outcomes associated with a low-carbohydrate diet for both weight loss and metabolic parameters as compared with a low-fat diet ${ }^{(4,11-13)}$. However, other comparative studies on low-fat diet, low-carbohydrate diet and other types of diets, as well as systematic reviews, have shown inconsistent results ${ }^{(5,14-16)}$.

One major problem with the classification of diets based on macronutrient proportions is the allocation of complex carbohydrate, dietary fibre and refined carbohydrate into the same category as 'carbohydrate'. Diets high in fibre, such as the Mediterranean diet, have been associated with improved insulin sensitivity $^{(4,17)}$, whereas diets high in refined carbohydrate have been associated with insulin resistance ${ }^{(18)}$. Thus, these findings suggest the need to develop a better index to classify diets based on the 'quality' of carbohydrate.

East Asians carry increased risk of developing insulin resistance and type 2 diabetes at a lower BMI as compared with Caucasians, partly owing to the tendency to accumulate excess body fat without large increases in $\mathrm{BMI}^{(19)}$. Studies on the relationship between dietary factors and insulin resistance are relatively scarce in East Asian populations ${ }^{(20-22)}$. In some studies

Abbreviations: $\beta 3 \mathrm{AR}, \beta-3$ adrenergic receptor; $\mathrm{F}: \mathrm{C}-\mathrm{R}$, fibre:carbohydrate ratio; HOMA-IR, homoeostasis model of assessment for insulin resistance. 
conducted among Chinese and Japanese, higher consumption of white rice was associated with increased risk of developing type 2 diabetes $^{(20,21)}$. However, one of these studies did not take into account the effect of dietary fibre in the analysis ${ }^{(21)}$, highlighting the need to investigate the relationship between the quality of carbohydrate and insulin resistance.

In this study, we examined the relationship between the ratio of dietary fibre to carbohydrate intake (fibre:carbohydrate ratio (F:C-R)) and insulin resistance and $\mathrm{HbA} 1 \mathrm{c}$, two strong indicators of future risk of diabetes, in Japanese adult subjects without diabetes participating in a 5-month diet and exercise programme. In addition, we examined the potential modification in association when accounting for individual carrier status of $\beta-3$ adrenergic receptor ( $\beta 3 A R$ ) functional gene polymorphism, a locus known to be associated with the risk of obesity ${ }^{(23-25)}$. We also investigated the longitudinal relationship between changes in the F:C-R and changes in homoeostasis model of assessment for insulin resistance (HOMA-IR) and HbA1c.

\section{Methods}

\section{Study population}

The Nutrition Clinic at Kagawa Nutrition University has a history of providing a diet and exercise programme for over 45 years $^{(26)}$. The clinic offers a voluntary 5-month diet and exercise programme semi-annually called the Healthy Diet Course. The participants include not only overweight/obese individuals, but also normal-weight individuals who have the desire to improve the quality of their diets. Participants are recruited through advertisements in television programmes and magazines on health and dieting, the website of the Nutrition Clinic, flyer distribution to participants attending seminars on nutrition at the Nutrition Clinic and annual invitation to individuals who have completed the programme previously via mail. The inclusion criteria for the programme are those aged 20 years or older and the absence of impairment in the knees or hip that limits mobility (walking up and downstairs).

At the beginning and end of the sessions, participants undergo anthropometric measurements and biochemical analyses of blood samples. During the 5-month period, participants are required to attend 12 sessions at the Nutrition Clinic. Each session, usually lasting for $6 \mathrm{~h}$, consists of group sessions, individual nutritional counselling, lectures, cognitive behavioural therapy and exercise regimen. In group sessions, registered dietitians give lectures on food selection and cooking. In individual nutritional counselling, dietitians review participants' diet records and advise participants to ensure that their meals consist of grains, main dish and side dish, and to increase the amount of vegetables, mushrooms and seaweeds that are rich in dietary fibres. The counselling is conducted based on Dietary Reference Intakes of Japanese People 2010, which recommends males and females at 18 years or older to consume over 19 and $17 \mathrm{~g}$ of dietary fibre, respectively ${ }^{(27)}$. At ten of the twelve sessions, participants are provided with lunch, which consists of germ rice, main dish (fish or meat), side dishes (vegetables, mushrooms and/or seaweeds), soup and dessert (fruits). Each lunch contains approximately $2510 \mathrm{~kJ}$
( $600 \mathrm{kcal})$ of total energy, $10 \mathrm{~g}$ of dietary fibre and $<3 \mathrm{~g}$ of salt. Participants are also given lectures on lifestyle-related disease and genetics by a medical doctor. Exercise regimen is a 70-min session led by a health fitness programmer, and consists of the use of rubber bands, balance balls, chairs, stretching, squatting and gymnastics that are intended to strengthen the pelvic joint, bones and muscles.

A total of 223 participants were enrolled in the programme between October 2006 and March 2015. Of the 223 participants of both sexes, those missing data on baseline body weight, percentage body fat and energy intake were excluded, resulting in 217 participants with complete baseline data. Of the 217 participants, those with diabetes ( $n$ 27) were excluded, leaving 190 participants for our cross-sectional analyses. Participants were considered to have diabetes if they met any of the following criteria: baseline HbA1c of $6.5 \%$ or higher ${ }^{(28,29)}$, use of antihyperglycaemic medication or prior diagnosis of diabetes. Of the 190 participants, those missing data on body weight, percentage body fat and energy intake at the end of the programme were excluded, leaving 177 participants for the longitudinal analyses. For those who were enrolled in the programme more than once during the period, we used data from the initial enrolment.

This study was conducted according to the guidelines laid down in the Declaration of Helsinki and all procedures involving human subjects/patients were approved by the Institutional Review Board of Kagawa Nutrition University. Written informed consent was obtained from all subjects ( $n$ 223).

\section{Anthropometric data}

Height was measured to the nearest millimetres by a standiometer (A\&D Company, Limited). Weight and percentage body fat were measured by dual X-ray absorptiometry (DEXA) (Osteometer, Toyo Medic). Weight was measured to the nearest $0 \cdot 1 \mathrm{~kg}$. Body fat mass was calculated by multiplying body weight and percentage body fat as measured by DEXA. Lean body mass was calculated by subtracting body fat mass from body weight ${ }^{(30)}$. BMI was calculated by dividing weight in kilograms by height in metres squared.

\section{Dietary and lifestyle data}

Each participant completed 3-d diet records at the beginning and at the end of the programme. To improve accuracy, participants were advised to measure the amount of food they ate by weighing each food with a scale. Registered dietitians reviewed each participant's diet records and interviewed each participant regarding the amount of food consumed to detect missing food or inconsistent reporting. When the reported amount of food items appeared obviously incorrect, dietitians corrected it based on a food database of the food items and confirmed it with the participant. Mean nutrient intakes per day were calculated by entering the diet record data into a diet analysis program (Excel Eiyo-kun, version 6.0; Kenpaku-sha). A ratio of fibre intake to carbohydrate intake (F:C-R) was calculated by dividing fibre intake by total carbohydrate intake and multiplying it by 100 .

We assessed the validity of self-reported diet records at baseline through the Goldberg $\operatorname{method}^{(31)}$. Specifically, we 
compared the group mean of reported energy intake with the BMR ratio (EI:BMR) and the $95 \%$ lower or upper confidence limit calculated by the following formula: $\operatorname{PAL} \times \exp \{\mathrm{SD} \times$ $[(S / 100) / \sqrt{ } n]\}$, where PAL is the mean physical activity level for the study group, SD -2 for the $95 \%$ lower confidence limit and +2 for the $95 \%$ upper confidence limit, and $n$ the number of subjects in the study ${ }^{(31)}$. $S$ refers to the factor that takes into consideration the variation in intake, BMR and energy requirement, and is given by the following formula: $S=\left[\left(\mathrm{CV}_{\mathrm{wFI}}\right)^{2} / d+\left(\mathrm{CV}_{\mathrm{wB}}\right)^{2}+\left(\mathrm{CV}_{\mathrm{tP}}\right)^{2}\right]^{1 / 2}$, where $\mathrm{CV}_{\mathrm{wFI}}$ is the within-subject $\mathrm{CV}$ in energy intake, $d$ the number of days of diet records, $\mathrm{CV}_{\mathrm{wB}}$ the $\mathrm{CV}$ of repeated $\mathrm{BMR}$ measurements or the precision of estimated compared with measured $\mathrm{BMR}$ and $\mathrm{CV}_{\mathrm{tP}}$ the total variation in $\mathrm{PAL}^{(31)}$. For our calculation, we set PAL as $1 \cdot 55$, which is the value used by the World Health Organization for 'light' activity ${ }^{(31)}$. We used the following $\mathrm{CV}$ values $\left(\mathrm{CV}_{\mathrm{wEI}}\right.$ $\left.23 \%, \mathrm{CV}_{\mathrm{wB}} 8.5 \%, \mathrm{CV}_{\mathrm{tP}} 15 \%\right)$ as applied in a previous Japanese study $^{(32)}$. As for BMR, we used the weight-adjusted predictive equation given in the Dietary Reference Intakes for Japanese, $2010^{(33)}$. The absence of under-reporting or over-reporting is suggested by an EI:BMR within the range of the $95 \%$ lower and upper confidence limits ${ }^{(31)}$.

Average number of steps per day was the mean of steps taken a day for $7 \mathrm{~d}$ as measured by a pedometer (Tanita). The measurement was done during the 1st week of the programme and at the end of the programme.

\section{Biochemical profile and blood pressure data}

Fasting blood samples were collected after overnight fasting at the beginning and end of the programme. Blood samples were sent to LSI Medience Corporation for the analyses of biochemical profile. Complete blood counts, serum levels of electrolytes, liver enzymes, glucose, insulin, HbA1c, total cholesterol, LDLcholesterol, HDL-cholesterol and TAG were measured. HOMA-IR was calculated by the following formula: (fasting plasma insulin $\times$ fasting plasma glucose $(\mathrm{mg} / \mathrm{dl})) / 405$ ((fasting plasma insulin $\times$ fasting plasma glucose $(\mathrm{mmol} / \mathrm{l})) / 22 \cdot 5)^{(34)}$

Blood pressure was measured in the seated position with the arm at the level of the heart using a TM-2665P Automatic Tabletop Blood Pressure Monitor (A\&D Medical) at the beginning and end of the programme.

\section{Genetic polymorphism data}

$\beta 3 A R$ are mainly expressed on adipose cells and play an important role in lipolysis and thermogenesis ${ }^{(23)}$. Participants were genotyped for $\beta 3 A R$ gene by PaGE Science Co., Ltd, because the variant of $\beta 3 A R$ (Trp64Arg) has been associated with higher $\mathrm{BMI}^{(24,25)}$ and increased capacity to gain weight ${ }^{(23)}$. Those who had at least one Trp64Arg allele (rs4994) were considered carriers

\section{Statistical analysis}

For the cross-sectional descriptive analyses of the baseline data, we divided the subjects into two groups using the 50th percentile value of the F:C-R as a cut-off and labelled the groups as high- and low-ratio groups. This was used in a bivariate analysis to compare mean values of anthropometric, metabolic and dietary parameters using the Student's $t$ test, and proportion of female participants, carriers of $\beta 3 A R$ polymorphism and individuals taking medications for dyslipidaemia and hypertension using the $\chi^{2}$ test.

Next, we used multivariable regression to investigate the independent association between the F:C-R and HOMA-IR after controlling for potential confounders. HOMA-IR was logtransformed and initial selection of variables into the multivariable model was based on clinical hypotheses regarding factors thought to affect HOMA-IR, as well as consideration of the association results from the bivariate analyses. The same covariates were considered in the analysis of the F:C-R and HbA1c. For the longitudinal analysis, we evaluated the relationship between absolute changes in F:C-R and changes in HOMA-IR or HbA1c using multivariable linear regression adjusting for potential confounders. We ran the model including change in the F:C-R, age, sex and variables that showed suggestive associations $(P$-value $<0 \cdot 20)$ in the unadjusted analyses. Variables were excluded in a step-wise manner if they did not influence the F:C-R association. We presented coefficients, $95 \%$ $\mathrm{CI}$ and $P$-values for each variable.

Additionally for each model, we tested the presence of multicollinearity by checking variance inflation factors (VIFs) and excluded variables with high VIF until all included variables had VIF of $<5$. We performed all statistical analyses in STATA 13 (StataCorp LP) and Microsoft Excel. We considered a two-tailed $P<0.05$ as statistically significant.

\section{Results}

The cross-sectional analyses were performed on 190 participants (180 female and ten male; aged 21-78 years) based on baseline data, and the longitudinal evaluations included a large subset of 177 participants (168 female and nine male) who also had complete follow-up data. Regarding the validity of selfreported diet records, we found the EI:BMR to be within the range of the $95 \%$ lower and upper confidence limits, suggesting the absence of under-reporting or over-reporting as a group.

Median baseline F:C-R among the participants was 6.38 . Table 1 shows the means of demographic, anthropometric, metabolic and dietary variables in the high F:C-R group (above median value) and low-ratio group (below median value). Compared with the low F:C-R group, the high-ratio group showed significantly lower mean body weight $(61.9 v .66 .4 \mathrm{~kg}$, $P=0.004)$ and lean body mass $(40 \cdot 1 v .42 \cdot 8 \mathrm{~kg}, P=0.002)$. A similar relationship was observed for body fat mass $(P=0.054)$. The high F:C-R group also showed lower mean fasting serum insulin levels $(6.5 v .8 .6 \mu \mathrm{U} / \mathrm{ml}, P<0.001)$ and HOMA-IR $(1.5 v$. $2 \cdot 0, P=0 \cdot 002)$. Mean HbA1c level also appeared lower in the high F:C-R group as compared with the low F:C-R group, which approached statistical significance $(5 \cdot 6 v .5 \cdot 7 \%, P=0.081)$. The high F:C-R group had significantly higher mean intake of protein $(73.5 v .68 .5 \mathrm{~g}, P=0.026)$, grams of protein intake per $\mathrm{kg}$ of standard weight $(1.4 v .1 .2 \mathrm{~g} / \mathrm{kg}$ standard weight, $P=0.002)$ and percentage energy from protein $(16.6 v .15 .0 \%, P<0.001)$ than 
Table 1. Baseline characteristics of study participants divided by fibre:carbohydrate ratio (F:C-R*) (Mean values with their standard errors; numbers and percentages)

\begin{tabular}{|c|c|c|c|c|c|}
\hline & \multicolumn{2}{|c|}{ High F:C-R group ( $n$ 95) } & \multicolumn{2}{|c|}{ Low F:C-R group ( $n$ 95) } & \multirow{2}{*}{$\frac{\text { Between-group comparison }}{P}$} \\
\hline & Mean & SE & Mean & SE & \\
\hline Age (years) & 56.7 & $1 \cdot 20$ & 54.1 & 1.04 & 0.104 \\
\hline \multicolumn{6}{|l|}{ Sex } \\
\hline Female & \multirow{2}{*}{\multicolumn{2}{|c|}{93}} & \multirow{2}{*}{\multicolumn{2}{|c|}{87}} & 0.051 \\
\hline$n$ & & & & & \\
\hline$\%$ & \multicolumn{2}{|c|}{98} & \multicolumn{2}{|c|}{92} & \\
\hline \multicolumn{6}{|l|}{ Male } \\
\hline$n$ & \multicolumn{2}{|c|}{2} & \multicolumn{2}{|c|}{8} & \\
\hline$\%$ & & & & & \\
\hline$\beta 3 A R$ polymorphism & & & & & \\
\hline Non-carrier & & & & & 0.223 \\
\hline$n$ & & & & & \\
\hline$\%$ & & & & & \\
\hline Trp64Arg carrier & & & & & \\
\hline$n$ & & & & & \\
\hline$\%$ & & & & & \\
\hline Anthropometrics & & & & & \\
\hline Weight (kg) & 61.9 & 0.94 & $66 \cdot 4$ & $1 \cdot 18$ & 0.004 \\
\hline $\mathrm{BMI}\left(\mathrm{kg} / \mathrm{m}^{2}\right)$ & $25 \cdot 6$ & 0.40 & $26 \cdot 6$ & 0.43 & 0.093 \\
\hline$\%$ Body fat & 34.7 & 0.56 & 35.1 & 0.61 & 0.664 \\
\hline Body fat mass $(\mathrm{kg})$ & 21.8 & 0.59 & 23.6 & 0.71 & 0.054 \\
\hline Lean body mass $(\mathrm{kg})$ & 40.1 & 0.48 & $42 \cdot 8$ & 0.66 & 0.002 \\
\hline Average steps taken per $d$ & $6777 \cdot 6$ & 403.67 & $6700 \cdot 7$ & 338.10 & 0.884 \\
\hline Biochemical profile & & & & & \\
\hline Fasting plasma glucose $(\mathrm{mg} / \mathrm{dl}) \dagger$ & 92.0 & 1.12 & 93.2 & 1.22 & 0.482 \\
\hline Fasting plasma insulin & 6.5 & 0.33 & 8.6 & 0.54 & $<0.001$ \\
\hline HOMA-IR & 1.5 & 0.09 & 2.0 & 0.15 & 0.002 \\
\hline HbA1c (\%, NGSP) & $5 \cdot 6$ & 0.04 & 5.7 & 0.04 & 0.081 \\
\hline $\mathrm{HbA} 1 \mathrm{c}(\mathrm{mmol} / \mathrm{mol}, \mathrm{IFCC})$ & 38 & 0.41 & 39 & 0.40 & 0.081 \\
\hline TAG (mg/dl) $\dagger$ & $103 \cdot 2$ & 6.66 & $108 \cdot 8$ & 5.53 & 0.523 \\
\hline Total cholesterol $(\mathrm{mg} / \mathrm{dll}) \dagger$ & 224.6 & 3.92 & 221.9 & 3.25 & 0.587 \\
\hline LDL-cholesterol $(\mathrm{mg} / \mathrm{dl}) \dagger$ & $136 \cdot 8$ & 3.49 & 137.6 & 3.11 & 0.877 \\
\hline HDL-cholesterol $(\mathrm{mg} / \mathrm{dl}) \dagger$ & 65.6 & 1.44 & 63.7 & 1.39 & 0.332 \\
\hline Blood pressure & & & & & \\
\hline Systolic $(\mathrm{mmHg})$ & $128 \cdot 8$ & $2 \cdot 14$ & $132 \cdot 0$ & 1.61 & 0.232 \\
\hline Diastolic (mmHg) & 78.5 & 1.23 & 80.7 & 1.14 & 0.186 \\
\hline Dietary variables & & & & & \\
\hline Energy intake (kJ) & 7455.4 & $146 \cdot 81$ & $7599 \cdot 2$ & 147.57 & \\
\hline Carbohydrate intake (g) & 242.4 & 5.54 & $247 \cdot 3$ & 5.08 & 0.513 \\
\hline Fat intake (g) & 55.1 & 1.42 & $56 \cdot 0$ & 1.63 & 0.654 \\
\hline Protein intake $(\mathrm{g})$ & 73.5 & 1.52 & 68.5 & 1.62 & 0.026 \\
\hline Protein intake $(\mathrm{g} / \mathrm{kg}$ standard weight) & 1.4 & 0.03 & 1.2 & 0.03 & 0.002 \\
\hline$\%$ Energy from carbohydrate & 54.4 & 0.59 & 54.8 & 0.67 & 0.607 \\
\hline$\%$ Energy from fat & $27 \cdot 8$ & 0.49 & $27 \cdot 6$ & 0.54 & 0.720 \\
\hline$\%$ Energy from protein & $16 \cdot 6$ & 0.19 & $15 \cdot 0$ & 0.18 & $<0.001$ \\
\hline Salt intake $(\mathrm{g})$ & 9.2 & 0.27 & $9 \cdot 0$ & 0.26 & 0.658 \\
\hline Fibre intake (g) & $19 \cdot 3$ & 0.51 & $12 \cdot 8$ & 0.34 & $<0.001$ \\
\hline $\mathrm{F}: \mathrm{C}-\mathrm{R}$ & 8.0 & 0.14 & 5.2 & 0.10 & $<0.001$ \\
\hline Medication use & & & & & \\
\hline For dyslipidaemia (yes) & & & & & 0.492 \\
\hline$n$ & & & & & \\
\hline$\%$ & & & & & \\
\hline For hypertension (yes) & & & & & 0.329 \\
\hline$n$ & & & & & \\
\hline$\%$ & & & & & \\
\hline Energy intakes by food groups (kJ) & & & & & \\
\hline Milk products & $431 \cdot 0$ & 35.96 & $421 \cdot 7$ & 35.72 & 0.854 \\
\hline Eggs & $214 \cdot 8$ & 15.55 & 213.7 & 14.49 & 0.959 \\
\hline Fish & 542.7 & 31.39 & 434.4 & 31.07 & 0.015 \\
\hline Meat & $622 \cdot 7$ & 45.01 & 669.7 & 40.03 & 0.437 \\
\hline Beans & 366.5 & 27.69 & $246 \cdot 1$ & 21.96 & 0.001 \\
\hline Green/yellow vegetables & $202 \cdot 7$ & 11.34 & 144.9 & 11.32 & $<0.001$ \\
\hline Plain-coloured vegetables & 228.5 & 13.09 & 153.2 & $7 \cdot 19$ & $<0.001$ \\
\hline Mushrooms and seaweeds & $36 \cdot 2$ & 2.66 & $19 \cdot 2$ & $2 \cdot 10$ & $<0.001$ \\
\hline Potatoes & 142.6 & $18 \cdot 22$ & 130.4 & 26.03 & 0.702 \\
\hline Fruit & 381.1 & 29.63 & 236.3 & 20.53 & $<0.001$ \\
\hline Grains & 2603.4 & 67.19 & 2935.8 & $74 \cdot 30$ & 0.001 \\
\hline Sugar food & $114 \cdot 3$ & 10.39 & $146 \cdot 2$ & 14.55 & 0.076 \\
\hline Oil food & 380.8 & 25.62 & 466.2 & 27.85 & 0.025 \\
\hline Other food & $1174 \cdot 1$ & $74 \cdot 30$ & 1363.0 & 71.24 & 0.068 \\
\hline
\end{tabular}

$\beta 3 A R, \beta-3$ adrenergic receptor; HOMA-IR, homoeostasis model of assessment for insulin resistance; NGSP, National Glycohemoglobin Standardization Program; IFCC, International Federation of Clinical Chemistry and Laboratory Medicine.

${ }^{*} \mathrm{~F}: \mathrm{C}-\mathrm{R}$ was calculated by dividing fibre intake by total carbohydrate intake and multiplying it by 100 .

† To convert glucose in $\mathrm{mg} / \mathrm{dl}$ to $\mathrm{mmol} / \mathrm{l}$, multiply by 0.0555 ; to convert TAG in $\mathrm{mg} / \mathrm{dl}$ to $\mathrm{mmol} / \mathrm{l}$, multiply by 0.0113 ; to convert cholesterol in $\mathrm{mg} / \mathrm{dl}$ to $\mathrm{mmol} / \mathrm{l}$, multiply by 0.0259 .

‡ A standard weight for each participant was calculated by multiplying the square of height in metres by 22 . 
Table 2. Coefficients of variables included in the multiple linear regression models for baseline log homoeostasis model of assessment for insulin resistance (HOMA-IR) and $\mathrm{HbA1c}{ }^{*}$ (Coefficients and $95 \%$ confidence intervals)

\begin{tabular}{|c|c|c|c|c|c|c|}
\hline & \multicolumn{3}{|c|}{ Log HOMA-IR ( $n$ 190) } & \multicolumn{3}{|c|}{$\mathrm{HbA1c}(n 190)$} \\
\hline & Coefficients & $95 \% \mathrm{Cl}$ & $P$ & Coefficients & $95 \% \mathrm{Cl}$ & $P$ \\
\hline $\mathrm{F}: \mathrm{C}-\mathrm{R} \dagger$ & -0.030 & $-0.077,0.017$ & 0.214 & -0.007 & $-0.036,0.022$ & 0.615 \\
\hline Age (years) & 0.005 & $-0.003,0.012$ & 0.225 & 0.012 & $0.007,0.017$ & $<0.001$ \\
\hline Sex & -0.736 & $-1 \cdot 215,-0.257$ & 0.003 & 0.095 & $-0.200,0.390$ & 0.526 \\
\hline$\beta 3 A R$ polymorphism & 0.218 & $0.052,0.384$ & 0.010 & 0.081 & $-0.021,0.183$ & 0.120 \\
\hline Body fat mass $(\mathrm{kg})$ & 0.054 & $0.037,0.072$ & $<0.001$ & 0.010 & $-0.001,0.021$ & 0.065 \\
\hline Lean body mass (kg) & -0.012 & $-0.034,0.011$ & 0.303 & 0.008 & $-0.006,0.021$ & 0.269 \\
\hline Average steps (per 1000 steps) & -0.010 & $-0.032,0.012$ & 0.368 & -0.001 & $-0.015,0.012$ & 0.843 \\
\hline Carbohydrate intake (per $10 \mathrm{~g}$ ) & 0.007 & $-0.013,0.027$ & 0.498 & -0.0004 & $-0.013,0.012$ & 0.947 \\
\hline Fat intake (per $10 \mathrm{~g}$ ) & -0.027 & $-0.097,0.044$ & 0.457 & 0.022 & $-0.022,0.065$ & 0.324 \\
\hline Protein intake (per $10 \mathrm{~g}$ ) & -0.045 & $-0.126,0.036$ & 0.272 & 0.005 & $-0.045,0.055$ & 0.843 \\
\hline$R^{2}$ & & 0.3146 & & & 0.2041 & \\
\hline$P$ & & $<0.001$ & & & $<0.001$ & \\
\hline \multicolumn{7}{|l|}{ Variance inflation factor } \\
\hline Mean & & 1.76 & & & 1.76 & \\
\hline Range & & $1.05-2.72$ & & & $1.05-2.72$ & \\
\hline
\end{tabular}

$\mathrm{F}: \mathrm{C}-\mathrm{R}$, fibre to carbohydrate ratio; $\beta 3 A R, \beta-3$ adrenergic receptor.

* Baseline energy intake was included in the original model; however, the variable was excluded from the final model owing to multicollinearity. $\dagger \mathrm{F}: \mathrm{C}-\mathrm{R}$ was calculated by dividing fibre intake by total carbohydrate intake and multiplying it by 100 .

did the low-ratio group. Fibre intake was also significantly greater in the high-ratio group as compared with the low-ratio group (19.3 v. 12.8 g, $P<0 \cdot 001)$, but the two groups showed similar mean total carbohydrate intake $(242.4 v .247 .3 \mathrm{~g}$, $P=0.513)$ and fat intake $(55 \cdot 1 v .56 \cdot 0 \mathrm{~g}, P=0.654)$. As for energy intakes by food groups, the high F:C-R group had significantly greater energy intakes from fish, beans, green/yellow vegetables, plain-coloured vegetables, mushrooms and seaweeds, and fruits, and lower energy intakes from grains and oil food as compared with the low F:C-R group.

Table 2 shows results of the multivariable linear regression analysis evaluating the association between F:C-R and log HOMA-IR and HbA1c levels at baseline, adjusting for age, sex, $\beta 3 A R$ polymorphism, body fat mass, lean body mass, average number of steps taken and intakes of total energy, carbohydrate, fat and protein. F:C-R was not associated with $\log$ HOMA-IR $(P=0.214)$, whereas sex, $\beta 3 A R$ polymorphism and body fat mass were significantly associated with log HOMA-IR. In the multivariable analysis of baseline HbA1c level, F:C-R was not significantly associated with HbA1c $(P=0.615)$, whereas increasing age was positively associated with HbA1c $(P<0.001)$.

Online Supplementary Table S1 shows changes in energy intakes by food groups across the 5-month study period. On average, participants increased their energy intakes from beans, green/yellow vegetables, plain-coloured vegetables, mushrooms and seaweeds, potato and fruits, whereas their energy intakes from milk, egg, fish, meat, grain, sugar food, oil food and other food decreased.

Table 3 presents results of the analysis evaluating factors associated with changes in HOMA-IR. The unadjusted analysis showed that increases in the F:C-R during the 5-month followup was associated with a reduction in HOMA-IR $(P=0.009)$. Adjustment for other covariates attenuated the association $(P=0.093)$. The covariates included age, sex, $\beta 3 A R$ polymorphism, baseline measures (HOMA-IR, body fat mass, lean body mass, average number of steps taken, intakes of total energy, carbohydrate, fat, protein and F:C-R) and changes in average number of steps taken, change in intakes of total energy, carbohydrate, fat and protein, and percentage changes in body fat mass and lean body mass. Inclusion of percentage change in body fat mass, a hypothesised intermediate in the causal pathway, in the model greatly attenuated the association between the F:C-R change and HOMA-IR change $(P=0.515)$.

Table 4 shows the regression coefficients for variables included in the multivariable models for changes in HbA1c. Increases in the F:C-R during the 5-month follow-up was associated with a reduction in HbA1c $(P<0.001)$, even after adjusting for potential confounders, including age, sex, $\beta 3 A R$ polymorphism, baseline measures (HbA1c, body fat mass, lean body mass, average number of steps taken, intakes of total energy, carbohydrate, fat and protein, and F:C-R) and changes in average number of steps taken; change in intakes of total energy, carbohydrate, fat and protein; and percentage changes in body fat mass and lean body mass. In addition, a higher baseline HbA1c level was associated with greater decreases in HbA1c in the multivariable model $(P<0 \cdot 001)$.

Because $\beta 3 A R$ polymorphism was significantly associated with log-transformed baseline HOMA-IR, we evaluated the presence of effect modification (statistical interaction) by the polymorphism. The interaction model (including a term representing the product of the baseline F:C-R and carrier status of the $\beta 3 A R$ polymorphism) adjusting for potential confounders approached statistical significance $(P=0.093)$, suggesting potential heterogeneity in effect of $\mathrm{F}$ : C-R on HOMA-IR by $\beta 3 A R$ polymorphism carrier status. In stratified multivariable analyses, the baseline F:C-R was not significantly associated with baseline $\log$ HOMA-IR (coefficient $=0.0141, P=0.647$ ) in non-carrier participants; however, in participants carrying the polymorphism, F:C-R was inversely associated with log HOMA-IR (coefficient $=-0 \cdot 0970, P=0 \cdot 018$ ). 
Table 3. Coefficients of variables included in the multiple linear regression models for changes in homoeostasis model of assessment for insulin resistance (HOMA-IR)

\begin{tabular}{|c|c|c|c|c|}
\hline & \multicolumn{4}{|c|}{ Change in HOMA-IR } \\
\hline & \multicolumn{2}{|c|}{ Unadjusted } & \multicolumn{2}{|c|}{ Adjusted ${ }^{*}$} \\
\hline & Coefficients & $P$ & Coefficients & $P$ \\
\hline \multicolumn{5}{|l|}{ Changes in } \\
\hline $\mathrm{F}: \mathrm{C}-\mathrm{R} \dagger$ & -0.095 & 0.009 & -0.044 & 0.09 \\
\hline Fibre intake $(\mathrm{g})$ & -0.023 & 0.124 & - & - \\
\hline Energy intake (per $100 \mathrm{kcal})$ & 0.019 & 0.391 & - & - \\
\hline Carbohydrate intake (per $10 \mathrm{~g}$ ) & 0.014 & 0.369 & - & - \\
\hline Fat intake (per $10 \mathrm{~g}$ ) & 0.021 & 0.675 & - & - \\
\hline Protein intake (per $10 \mathrm{~g}$ ) & -0.026 & 0.591 & - & - \\
\hline \multicolumn{5}{|l|}{ Percentage changes in } \\
\hline Body fat mass & 0.024 & 0.014 & - & - \\
\hline Lean body mass & -0.022 & 0.419 & - & - \\
\hline $\begin{array}{l}\text { Change in average steps } \\
\text { (per } 1000 \text { steps) }\end{array}$ & -0.030 & 0.174 & - & - \\
\hline Baseline HOMA-IR & -0.734 & $<0.001$ & -0.801 & $<0.00$ \\
\hline Age (per 10 years) & 0.009 & 0.906 & 0.077 & 0.11 \\
\hline Sex & 0.816 & 0.038 & - & - \\
\hline$\beta 3 A R$ polymorphism & -0.087 & 0.631 & - & - \\
\hline \multicolumn{5}{|l|}{ Baseline measures } \\
\hline Body fat mass $(\mathrm{kg})$ & -0.031 & 0.023 & 0.030 & 0.00 \\
\hline Lean body mass $(\mathrm{kg})$ & -0.045 & 0.003 & - & - \\
\hline Average steps (per 1000 steps) & 0.017 & 0.473 & - & - \\
\hline Energy intake (per $100 \mathrm{kcal})$ & -0.004 & 0.879 & - & - \\
\hline Carbohydrate intake (per $10 \mathrm{~g}$ ) & -0.012 & 0.471 & - & - \\
\hline Fat intake (per $10 \mathrm{~g}$ ) & 0.034 & 0.568 & - & - \\
\hline Protein intake (per $10 \mathrm{~g}$ ) & 0.060 & 0.286 & - & - \\
\hline $\mathrm{F}: \mathrm{C}-\mathrm{R} \dagger$ & 0.073 & 0.126 & -0.050 & \\
\hline \multicolumn{5}{|l|}{$\begin{array}{l}R^{2} \\
P \text { (model) }\end{array}$} \\
\hline$P$ (model) & & & $<0.00$ & \\
\hline \multicolumn{5}{|l|}{ Variance inflation factors } \\
\hline \multicolumn{5}{|l|}{ Mean } \\
\hline Range & & & $1.03-1$ & \\
\hline
\end{tabular}

$\mathrm{F}: \mathrm{C}-\mathrm{R}$, fibre:carbohydrate ratio; $\beta 3 A R, \beta-3$ adrenergic receptor

* The adjusted model initially included $\mathrm{F}: \mathrm{C}-\mathrm{R}$ change, age, sex and variables with a $P$-value $<0.20$ in the unadjusted analysis. Percentage change in body fat mass was excluded because it is considered to be in the pathway of F:C-R change leading to HOMA-IR change. Change in average steps, sex and baseline lean body mass were excluded from the model owing to the minimal influence on $\mathrm{F}: \mathrm{C}-\mathrm{R}$ change.

$\dagger F: C-R$ was calculated by dividing fibre intake by total carbohydrate intake and multiplying it by 100 .

\section{Discussion}

To the best of our knowledge, no past studies have specifically investigated the relationship between F:C-R and measures of glucose tolerance. We observed, in a cross-sectional analysis, that individuals with a higher ratio of fibre to carbohydrate intake had significantly lower HOMA-IR as compared with those with a lower ratio. Interestingly, the higher-ratio group and the lower-ratio group had very similar mean carbohydrate and fat intakes, as well as percentage energy from these nutrients; however, the two groups had significantly different HOMA-IR levels. This finding may suggest the presence of factors other than relative proportions of macronutrients that significantly affect insulin resistance.

We also demonstrated an inverse association between changes in F:C-R and changes in HbA1c after adjusting for potential confounders. The result suggests that, on average, participants with greater increase in the F:C-R over the 5-month period had greater reduction in HbA1c. Our results are supported by previous studies showing an association between higher fibre intake and lower risk of incident diabetes ${ }^{(6,7)}$. The analysis of HOMA-IR showed a similar association, which was
Table 4. Coefficients of variables included in the multiple linear regression models for changes in $\mathrm{HbA} 1 \mathrm{c}$

\begin{tabular}{|c|c|c|c|c|}
\hline & \multicolumn{4}{|c|}{ Change in $\mathrm{HbA} 1 \mathrm{c}$} \\
\hline & \multicolumn{2}{|c|}{ Unadjusted } & \multicolumn{2}{|c|}{ Adjusted* } \\
\hline & Coefficients & $P$ & Coefficients & $P$ \\
\hline \multicolumn{5}{|l|}{ Changes in } \\
\hline $\mathrm{F}: \mathrm{C}-\mathrm{R} \dagger$ & -0.029 & $<0.001$ & -0.028 & $<0.001$ \\
\hline Fibre intake $(\mathrm{g})$ & -0.009 & 0.001 & - & - \\
\hline Energy intake (per $100 \mathrm{kcal})$ & 0.005 & 0.248 & - & - \\
\hline Carbohydrate intake (per $10 \mathrm{~g}$ ) & 0.002 & 0.479 & - & - \\
\hline Fat intake (per $10 \mathrm{~g}$ ) & 0.013 & $0 \cdot 159$ & - & - \\
\hline Protein intake (per $10 \mathrm{~g}$ ) & -0.00003 & 0.998 & - & - \\
\hline \multicolumn{5}{|l|}{ Percentage changes in } \\
\hline Body fat mass & 0.005 & 0.007 & - & - \\
\hline Lean body mass & -0.003 & 0.534 & - & - \\
\hline $\begin{array}{l}\text { Change in average steps } \\
\text { (per } 1000 \text { steps) }\end{array}$ & 0.0001 & 0.979 & - & - \\
\hline Baseline $\mathrm{HbA1c}$ & -0.262 & $<0.001$ & -0.276 & $<0.001$ \\
\hline Age (per 10 years) & 0.002 & 0.893 & 0.033 & 0.019 \\
\hline Sex & 0.049 & 0.521 & - & - \\
\hline$\beta 3 A R$ polymorphism & -0.014 & 0.685 & - & - \\
\hline \multicolumn{5}{|l|}{ Baseline measures: } \\
\hline Body fat mass (kg) & -0.005 & 0.037 & - & - \\
\hline Lean body mass $(\mathrm{kg})$ & -0.006 & 0.048 & - & - \\
\hline Average steps (per 1000 steps) & -0.001 & 0.879 & - & - \\
\hline Energy intake (per $100 \mathrm{kcal})$ & -0.006 & 0.233 & - & - \\
\hline Carbohydrate intake (per $10 \mathrm{~g}$ ) & -0.002 & 0.474 & - & - \\
\hline Fat intake (per $10 \mathrm{~g}$ ) & -0.008 & 0.496 & - & - \\
\hline Protein intake (per $10 \mathrm{~g}$ ) & -0.009 & 0.417 & - & - \\
\hline $\mathrm{F}: \mathrm{C}-\mathrm{R} \dagger$ & 0.013 & $0 \cdot 157$ & -0.009 & 0.307 \\
\hline$R^{2}$ & & & 0.28 & \\
\hline$P$ (model) & & & $<0.00$ & \\
\hline \multicolumn{5}{|l|}{ Variance inflation factors } \\
\hline Mean & & & $1 \cdot 26$ & \\
\hline Range & & & $1 \cdot 14-1$ & 37 \\
\hline
\end{tabular}

F:C-R, fibre:carbohydrate ratio; ; $\beta 3 A R, \beta-3$ adrenergic receptor.

* The adjusted model initially included F:C-R change, age, sex and variables with a $P$-value $<0.20$ in the unadjusted analysis. Percentage change in body fat mass was excluded because it is considered to be in the pathway of $\mathrm{F}: \mathrm{C}-\mathrm{R}$ change leading to $\mathrm{HbA1c}$ change. Change in fat intake, sex, baseline body fat mass and lean body mass were excluded from the model owing to the minimal influence on $F: C-R$ change.

† F:C-R was calculated by dividing fibre intake by total carbohydrate intake and multiplying it by 100 .

not, however, statistically significant after adjustment for potential confounders. The disparity in association could be attributed to the possibility that an increase in F:C-R may result in reduced postprandial glucose levels, which are more strongly correlated with HbA1c levels as compared with fasting plasma glucose levels ${ }^{(35)}$. Some studies have shown that soluble dietary fibre can help reduce postprandial glucose levels potentially through slowing the rate of glucose absorption in the intestine ${ }^{(36,37)}$. Increase in F:C-R may have had smaller effects on fasting plasma glucose levels, which were used to calculate HOMA-IR, over the study period.

Interestingly, we also observed evidence that the Trp64Arg polymorphism may modify the relationship between the F:C-R and baseline HOMA-IR. The ratio was inversely associated with $\log$ HOMA-IR at baseline in carriers. The variant of the $\beta 3 A R$ gene (Trp64Arg) has been considered one candidate locus that increases susceptibility to obesity and insulin resistance ${ }^{(23,38,39)}$. Some studies showed association of the variant with higher $\mathrm{BMI}^{(24,25)}$, increased capacity to gain weight ${ }^{(23)}$ and early onset of type 2 diabetes mellitus ${ }^{(38,39)}$, although not all studies support the association ${ }^{(40,41)}$. These studies did not account for dietary factors in their analyses ${ }^{(23-25,38-41)}$. Further investigation is 
warranted to evaluate whether carriers of this polymorphism may gain weight and develop insulin resistance more easily as compared with non-carriers if their F:C-R are low.

Our findings have significant implications on the dietary interventions aimed at type 2 diabetes prevention. Although results from some randomised trials favour low-carbohydrate diets as compared with high-carbohydrate diets ${ }^{(4,11-13)}$, our findings raise the possibility that a high-carbohydrate diet may be a feasible dietary strategy for diabetes prevention as long as $\mathrm{F}: \mathrm{C}-\mathrm{R}$ is maintained at a high level, as was the case for traditional Asian diets ${ }^{(42)}$. This possibility is important because diets relatively high in carbohydrate with a high F:C-R may be more sustainable than low-carbohydrate diets, which were shown to have higher attrition rates in some randomised trials lasting 1 year or longer ${ }^{(4,43)}$. Furthermore, a meta-analysis of observational studies showed increased risk of all-cause mortality in subjects on low-carbohydrate diets ${ }^{(44)}$. Long-term large-scale prospective studies are warranted to investigate the combined effects of different relative proportions of macronutrients and F:C-R on weight, metabolic profile and dropout rates.

Taking a ratio of fibre to carbohydrate intake may have an advantage over simply measuring the intake of fibre in terms of predicting the level of insulin resistance. Two individuals with equal intake of dietary fibre could have markedly different intakes of refined sugars and total energy, which likely affects their risk of developing insulin resistance ${ }^{(18)}$. F:C-R may differentiate such individuals and enable clinicians or dietitians to identify those at increased risk of metabolic disturbance. Given the scarcity of studies comparing the effect of diets with equal amount of fibre and different levels of total carbohydrate intakes, this topic warrants further investigation.

Among the fibre-containing food groups, the high F:C-R group had significantly greater energy intakes from beans, green/yellow vegetables, plain-coloured vegetables, mushrooms and seaweeds and fruits, as compared with the low F:C-R group. Frequently consumed foods for each of these food groups were as follows - (1) beans: tofu (firm tofu, silken tofu, fried tofu), natto (fermented soyabeans); (2) green/yellow vegetables: carrot, spinach, tomato, pumpkin, broccoli; (3) plain-coloured vegetables: daikon radish, onion, cabbage, Chinese cabbage, cucumber; (4) mushrooms and seaweeds: shimeji, shiitake, enokitake, wakame (sea mustard), hijiki; (5) fruits: banana, apple, mandarin. Taking the average F:C-R of these foods based on a Japanese food composition book (Excel Eiyo-kun, version 8.0) showed that mushrooms and seaweeds and beans had F:C-R above 50, and green/yellow vegetables and plain-coloured vegetables had F:C-R above 30. Thus, recommending foods from these food groups is likely to lead to practical dietary advice that can increase the F:C-R of a person's diet.

Our study has several strengths. First, a ratio of dietary fibre to carbohydrate intake may be easy for lay individuals who are not trained in dietetics to use. People can imagine that foods high in fibre, such as vegetables, legumes and brown rice, increase the ratio, whereas refined grains, sugary snacks and sweetened beverages increase total carbohydrate intake without increasing fibre intake, thus lowering the ratio. Thinking of how each food they consume changes their diet's overall F:C-R can help them design dietary regimens with favourable ratios that may improve their glucose tolerance. Second, our ability to investigate the association between longitudinal changes in F:C-R and glucose tolerance addressed the temporality assumption in causal inference and provided added confidence in the results. Third, the quality of dietary data obtained in this study is likely to be high because participants were encouraged to weigh the amount of food using a scale, and registered dietitians interviewed each participant regarding the amount of foods consumed and the seasonings used in order to improve the accuracy of the diet records. Moreover, we evaluated the validity of self-reported diet records by the Goldberg $\operatorname{method}^{(31)}$, which suggested the absence of under-reporting or over-reporting.

Our study also had limitations. First, the duration of the diet and exercise programme was 5 months. We cannot conclude whether our results are applicable for a longer period of time, but expect that dietary changes maintained beyond this period would provide sustained or additional improvements in insulin resistance parameters. Second, most of the participants were middle-aged or elderly Japanese women without diabetes. Thus, the findings from this study may not be extrapolated to other racial/ethnic groups or male subjects who are affected with diabetes. Whether a high F:C-R diet would help to improve glucose tolerance in patients with type 2 diabetes is uncertain and cannot be concluded from the study. However, our findings are important because research on patients without type 2 diabetes has been scarce. Third, it is possible that the 3-d diet records provided by the participants may not reflect their usual dietary intake; however, because the purpose of this selfinitiated voluntary 5-month programme was to improve their dietary habit, it is unlikely that they intentionally overestimated or underestimated their food intakes, as suggested by the validity evaluation using the Goldberg method ${ }^{(31)}$. Fourth, the actual amount of physical activity that participants engaged might not have been well captured by average number of steps taken per day, which was included in our analyses. Because physical activity has been shown to be associated with lower risk of incident type 2 diabetes $^{(45-47)}$, more accurate measures of physical activity would have improved the quality of our study. Fifth, intakes of simple carbohydrates, such as glucose and fructose, were not separately measured in this study. Because differential effects of these carbohydrates on metabolic disturbances have been demonstrated ${ }^{(48)}$, this topic merits further investigation in future studies. Last, although we considered a comprehensive breadth of potential confounders, like most observational studies, we cannot completely rule out the influence of residual confounding and/or unknown confounders. These limitations, however, are unlikely to undermine the significance of a $\mathrm{F}: \mathrm{C}-\mathrm{R}$ in diabetes prevention given supportive evidence derived from two different measures of glucose tolerance, the strength of associations with HbA1c and confirmation by longitudinal analyses in the context of previous supportive scientific literature.

\section{Conclusion}

We found that an increase in F:C-R was associated with a reduction in HbA1c in Japanese subjects enrolled in a 5-month 
diet and exercise programme. Our findings suggest the possibility that a relatively high-carbohydrate diet can be a viable strategy for diabetes prevention if a F:C-R is maintained at a high level. The relationship among relative proportions of macronutrients, F:C-R and insulin resistance merits further investigation. Overall, our findings strongly suggest the need to take into account the quality of carbohydrate, or a ratio of fibre to carbohydrate intake, in strategies aimed at type 2 diabetes prevention in East Asian populations.

\section{Acknowledgements}

The authors extend sincere appreciation to all staff members of the Nutrition Clinic for running the programme and collecting data.

This research received no specific grant from any funding agency or commercial or not-for-profit sectors.

N. M. and Akira T. formulated the research questions and designed the study; N. M., C. K., Airi T., K. K. and Akira T. carried out the study; N. M., C. K., Airi T., K. K., M. A., K. U. and Akira T. analysed data; C. K., Airi T., K. K., M. A., K. Y. U. and Akira T. revised critically for important intellectual content; Akira T. had primary responsibility for final content. All authors read and approved the final manuscript.

The authors declare that there are no conflicts of interest.

\section{Supplementary material}

For supplementary material/s referred to in this article, please visit https://doi.org/10.1017/S0007114517003725

\section{References}

1. Maki KC \& Phillips AK (2015) Dietary substitutions for refined carbohydrate that show promise for reducing risk of type 2 diabetes in men and women. J Nutr 145, 159S-163S.

2. Leon BM \& Maddox TM (2015) Diabetes and cardiovascular disease: epidemiology, biological mechanisms, treatment recommendations and future research. World J Diabetes $\mathbf{6}$, $1246-1258$

3. Alwahsh SM, Dwyer BJ, Forbes S, et al. (2017) Insulin production and resistance in different models of diet-induced obesity and metabolic syndrome. Int J Mol Sci 18, E285.

4. Shai I, Schwarzfuchs D, Henkin Y, et al. (2008) Weight loss with a low-carbohydrate, Mediterranean, or low-fat diet. $N$ Engl J Med 359, 229-241.

5. McAuley KA, Smith KJ, Taylor RW, et al. (2006) Long-term effects of popular dietary approaches on weight loss and features of insulin resistance. Int J Obes (Lond) 30, 342-349.

6. Meyer KA, Kushi LH, Jacobs DR, et al. (2000) Carbohydrates, dietary fiber, and incident type 2 diabetes in older women. $\mathrm{Am}$ J Clin Nutr 71, 921-930.

7. Schulze MB, Liu S, Rimm EB, et al. (2004) Glycemic index, glycemic load, and dietary fiber intake and incidence of type 2 diabetes in younger and middle-aged women. Am J Clin Nutr 80, 348-356.

8. Alwahsh SM, Xu M, Seyhan HA, et al. (2014) Diet high in fructose leads to an overexpression of lipocalin-2 in rat fatty liver. World J Gastroenterol 20, 1807-1821.

9. Ishimoto T, Lanaspa MA, Rivard CJ, et al. (2013) High-fat and high-sucrose (Western) diet induces steatohepatitis that is dependent on fructokinase. Hepatology 58, 1632-1643.
10. Samocha-Bonet D, Campbell LV, Mori TA, et al. (2012) Overfeeding reduces insulin sensitivity and increases oxidative stress, without altering markers of mitochondrial content and function in humans. PLOS ONE 7, e36320.

11. Bazzano LA, Hu T, Reynolds K, et al. (2014) Effects of lowcarbohydrate and low-fat diets: a randomized trial. Ann Intern Med 161, 309-318.

12. Foster GD, Wyatt HR, Hill JO, et al. (2003) A randomized trial of a low-carbohydrate diet for obesity. $N$ Engl J Med $\mathbf{3 4 8}$, 2082-2090

13. Foster GD, Wyatt HR, Hill JO, et al. (2010) Weight and metabolic outcomes after 2 years on a low-carbohydrate versus low-fat diet: a randomized trial. Ann Intern Med 153, 147-157.

14. Tobias DK, Chen M, Manson JE, et al. (2015) Effect of low-fat diet interventions versus other diet interventions on long-term weight change in adults: a systematic review and metaanalysis. Lancet Diabetes Endocrinol 3, 968-979.

15. Hession M, Rolland C, Kulkarni U, et al. (2009) Systematic review of randomized controlled trials of low-carbohydrate vs. low-fat/low-calorie diets in the management of obesity and its comorbidities. Obes Rev 10, 36-50.

16. Naude CE, Schoonees A, Senekal M, et al. (2014) Low carbohydrate versus isoenergetic balanced diets for reducing weight and cardiovascular risk: a systematic review and metaanalysis. PLOS ONE 9, e100652.

17. Salmeron J, Manson JE, Stampfer MJ, et al. (1997) Dietary fiber, glycemic load, and risk of non-insulin-dependent diabetes mellitus in women. JAMA 277, 472-477.

18. Barclay AW, Petocz P, McMillan-Price J, et al. (2008) Glycemic index, glycemic load, and chronic disease risk - a meta-analysis of observational studies. Am J Clin Nutr 87, 627-637.

19. Hsu WC, Araneta MR, Kanaya AM, et al. (2015) BMI cut points to identify at-risk Asian Americans for type 2 diabetes screening. Diabetes Care 38, 150-158.

20. Nanri A, Mizoue T, Noda M, et al. (2010) Rice intake and type 2 diabetes in Japanese men and women: the Japan Public Health Center-based Prospective Study. Am J Clin Nutr 92, 1468-1477.

21. Villegas R, Liu S, Gao YT, et al. (2007) Prospective study of dietary carbohydrates, glycemic index, glycemic load, and incidence of type 2 diabetes mellitus in middle-aged Chinese women. Arch Intern Med 167, 2310-2316.

22. Hu EA, Pan A, Malik V, et al. (2012) White rice consumption and risk of type 2 diabetes: meta-analysis and systematic review. BMJ 344, e1454

23. Clement K, Vaisse C, Manning BS, et al. (1995) Genetic variation in the beta 3 -adrenergic receptor and an increased capacity to gain weight in patients with morbid obesity. $N$ Engl J Med 333, 352-354.

24. Mitchell BD, Blangero J, Comuzzie AG, et al. (1998) A paired sibling analysis of the beta-3 adrenergic receptor and obesity in Mexican Americans. J Clin Invest 101, 584-587.

25. Kim-Motoyama H, Yasuda K, Yamaguchi T, et al. (1997) A mutation of the beta 3-adrenergic receptor is associated with visceral obesity but decreased serum triglyceride. Diabetologia 40, 469-472.

26. Kagawa Y \& Kagawa A (1984) Secondary prevention of cardiovascular diseases of outpatients of the nutrition clinic. In Nutritional Prevention of Cardiovascular Disease, pp. 339-348 [W Lovenberg and Y Yamori, editors]. New York: Academic Press.

27. Ministry of Health, Labour, and Welfare (2009) Dietary Reference Intakes for Japanese, 2010. Tokyo: Ministry of Health and Welfare (in Japanese). 
28. Kashiwagi A (2013) Development of the HbA1c international standardization of HbA1c measurement in Japan Diabetes Society. Rinsho Byori 61, 585-593 (Article in Japanese).

29. Kharroubi AT, Darwish HM, Al-Halaweh AIA, et al. (2014) Evaluation of glycated hemoglobin (HbA1c) for diagnosing type 2 diabetes and prediabetes among Palestinian Arab population. PLOS ONE 9, e88123.

30. Aloia JF, Vaswani A, Ma R, et al. (1995) Comparative study of body composition by dual-energy X-ray absorptiometry. J Nucl Med 36, 1392-1397.

31. Black AE (2000) Critical evaluation of energy intake using the Goldberg cut-off for energy intake: basal metabolic rate. A practical guide to its calculation, use and limitations. Int J Obes 24, 1119-1130.

32. Murakami K (2004) Critical examination of reported energy intake in published dietary studies of Japanese subjects using the Goldberg cut-off. J Nutr Sci Vitaminol 50, 165-170.

33. Miyake R, Tanaka S, Ohkawara K, et al. (2011) Validity of predictive equations for basal metabolic rate in Japanese adults. J Nutr Sci Vitaminol 57, 224-232.

34. Matthews DR, Hosker JP, Rudenski AS, et al. (1985) Homeostasis model assessment: insulin resistance and beta-cell function from fasting plasma glucose and insulin concentrations in man. Diabetologia 28, 412-419.

35. Ketema EB \& Kibret KT (2015) Correlation of fasting and postprandial plasma glucose with HbA1c in assessing glycemic control; systematic review and meta-analysis. Arch Public Health 73, 43-51.

36. Jenkins DJ, Wolever TM, Leads AR, et al. (1978) Dietary fibres, fibre analogues, and glucose tolerance: importance of viscosity. Br Med J 1, 1392-1394.

37. Jenkins DJ, Goff DV, Leeds AR, et al. (1976) Unabsorbable carbohydrates and diabetes: decreased post-prandial hyperglycaemia. Lancet ii, 172-174.

38. Walston J, Silver K, Bogardus C, et al. (1995) Time of onset of non-insulin-dependent diabetes mellitus and genetic variation in the beta 3-adrenergic-receptor gene. N Engl J Med 333, 343-347.
39. Walston J, Silver K, Hilfiker H, et al. (2000) Insulin response to glucose is lower in individuals homozygous for the Arg 64 variant of the beta-3-adrenergic receptor. J Clin Endocrinol Metab 85, 4019-4022.

40. Gagnon J, Mauriege P, Roy S, et al. (1996) The Trp64Arg mutation of the beta3 adrenergic receptor gene has no effect on obesity phenotypes in the Quebec Family Study and Swedish Obese Subjects cohorts. J Clin Invest 98, 2086-2093.

41. Elbein SC, Hoffman M, Barrett K, et al. (1996) Role of the beta 3-adrenergic receptor locus in obesity and noninsulin-dependent diabetes among members of Caucasian families with a diabetic sibling pair. J Clin Endocrinol Metab 81, 4422-4427.

42. Hsu WC, Lau KH, Matsumoto M, et al. (2014) Improvement of insulin sensitivity by isoenergy high carbohydrate traditional Asian diet: a randomized controlled pilot feasibility study. PLOS ONE 9, e106851.

43. Iqbal N, Vetter ML, Moore RH, et al. (2010) Effects of a lowintensity intervention that prescribed a low-carbohydrate vs. a low-fat diet in obese, diabetic participants. Obesity 18, 1733-1738.

44. Noto H, Goto A, Tsujimoto T, et al. (2013) Low-carbohydrate diets and all-cause mortality: a systematic review and metaanalysis of observational studies. PLOS ONE $\mathbf{8}$, e 55030.

45. Hu FB, Leitzmann MF, Stampfer MJ, et al. (2001) Physical activity and television watching in relation to risk for type 2 diabetes mellitus in men. Arch Intern Med 161, 1542-1548.

46. Hu FB, Li TY, Colditz GA, et al. (2003) Television watching and other sedentary behaviors in relation to risk of obesity and type 2 diabetes mellitus in women. JAMA 289, 1785-1791.

47. Honda T, Kuwahara K, Nakagawa T, et al. (2015) Leisuretime, occupational, and commuting physical activity and risk of type 2 diabetes in Japanese workers: a cohort study. $B M C$ Public Health 15, 1004.

48. Stanhope KL, Schwarz JM, Keim NL, et al. (2009) Consuming fructose-sweetened, not glucose-sweetened, beverages increases visceral adiposity and lipids and decreases insulin sensitivity in overweight/obese humans. J Clin Invest 119, 1322-1334. 